\title{
Different surveys provide similar pictures of trends in a marine fish community but not of individual fish populations
}

\author{
Verena M. Trenkel ${ }^{a^{*}}$, John K. Pinnegar ${ }^{b}$, Marie-Joëlle Rochet ${ }^{a}$ and Brian D. Rackham ${ }^{b}$ \\ a'Laboratoire MAERHA, IFREMER, Rue de l'lle d' Yeu, BP 21105, 44311, Nantes cedex 3, France \\ ${ }^{b}$ Centre for Environment, Fisheries and Aquaculture Science, Lowestoft Laboratory, Lowestoft NR33 OHT, \\ England, UK \\ *: Corresponding author : tel: +33 240 374053; fax: +33 240 374075. verena.trenkel@ifremer.fr
}

\begin{abstract}
Choice of sampling method and survey period can have an important impact on the perception of the structure and dynamics of an ecological community. For the Celtic Sea fish assemblage we compared data obtained by three different trawl surveys: an autumn groundfish survey with a GOV trawl, and a spring and an autumn groundfish survey, both carried out with a Portuguese high-headline trawl. Time-series of abundance estimates were not consistent among surveys for all species and were generally very noisy. An analysis of variance components showed that the sampling method contributed more to the variance in abundance estimates compared to survey period, interannual variability, or even sampling variance. Overall community assessments based on indicators such as proportions of non-commercial and piscivorous species, and the proportion of benthic species showed similar trends for all data series. The shape of the size spectrum based on abundances per length class summed over all fish species, although stable over time, was highly sensitive to the sampling method. With the exception of size spectra, community indicators for marine fish assemblages monitored by surveys seem to be robust to survey period and trawling gear, but species abundance trends are method dependent.
\end{abstract}

Keywords: abundance; Celtic Sea; size spectrum; species diversity; survey; trawl 


\section{Introduction}

Ecosystems and communities are no longer viewed as integrated selfregulating systems; rather they are recognised to be open and naturally changing systems that are subject to driving factors from outside (O'Neill, 2001). In this context, monitoring of an exploited community has become a challenge, because an appropriate sampling scheme for an entity whose spatial and taxonomic limits are not clearly defined is difficult to design and might have to vary on a seasonal basis. Problems with taxonomic resolution are common in community studies, resulting in misleading pictures of trophic structure and dynamics (Warwick and Clarke, 1996; Goldwasser and Roughgarden, 1997; Yodzis and Winnemiller, 1999). Moreover, values of many community attributes such as species diversity indices and estimates of species abundance change with increasing sampling effort (Soetaert and Heip, 1990; Cao et al., 2002; Hövemeyer and Stippich, 2000).

Both climate change and exploitation put stress on marine fish communities. Responsible fisheries management relies on accurate information concerning trends in both commercially exploited species and the community as a whole. Previous studies have demonstrated that the type of fishing gear used in research vessel surveys greatly influences the species composition obtained (Polovino et al., 1982). Even with a single standardized bottom-trawl, variations in catchability among vessels can lead to different indices of abundance for a given species and as a consequence, of relative community composition (Pelletier, 1998). Although gear type strongly influences the relative species composition of the catch (Kulbicki and Wantiez 1990; Merrett et al., 1991), integrated community attributes such as species diversity and evenness seem to be less affected (Wantiez, 1996).

Marine fish communities are modified gradually and major changes might only be detectable over long periods. Long time-series inherently suffer from changes in survey methodology. Thus, decadal trends in diversity and community structure as found, for example, for the North sea groundfish assemblage (Greenstreet et al., 1999) might partly be artefacts caused by vessel changes. Similarly, the significant long-term changes detected in the composition of Celtic sea fish community (Pinnegar et al., 2002) might unbeknowingly have been influenced by differences in crews and gear operation.

Usually sampling methods are standardized when several countries survey the same resources. However, the Celtic sea groundfish assemblage has been surveyed with different gears by France in autumn and by the UK in spring and autumn. Although the time series are relatively short, this rather unique situation offers the rare opportunity to study gear and season effects. We attempt to estimate the sampling bias associated with different survey designs by comparing the emergent pictures of the groundfish assemblage. We address two main questions: i) How large are the differences in abundance estimates between French and English surveys and between English spring and autumn surveys, compared to other sources of variability?; ii) How do these differences affect measured community attributes?

\section{Material and methods}

\section{- Surveys}

The Celtic sea is a continental shelf area bordered by Ireland in the North, the UK in the east and the Bay of Biscay (at $47^{\circ} \mathrm{N}$ ) in the south, and supports many valuable fisheries. We consider only the part (124505 $\left.\mathrm{km}^{2}\right)$ sampled regularly by all surveys (Figure 1). The study has been restricted to fish species, because invertebrate taxa were not identified uniformly during all surveys. Species belonging to the Ammodytidae, Argentinidae, Berycidae, Callionymidae, Gobiidae, Macrouridae, Myctophidae and Syngnatidae were combined, as individual species had not always been differentiated. Table 1 provides general survey information and gear specifications for the two countries. 
Figure 1. Celtic sea study area with UK fixed sampling stations (o) and French stratified random sampling stations in $2000(+)$.

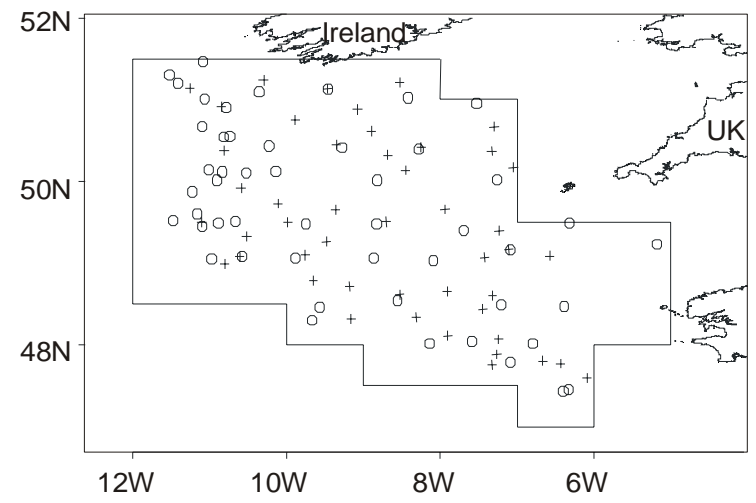

The original objective of the UK surveys, which commenced in 1981 , was to investigate the distribution and biology of the western mackerel scomber scombrus stock. The spring (s) survey targeted spawning adults, while the autumn (a) survey primarily targeted pre-recruits (Warnes and Jones, 1995). Prior to the early 1980s, the fishery for mackerel had greatly expanded and concerns had been voiced about potential overexploitation of this stock (Lockwood and Shepherd, 1984). Subsequently (after 1982), with increasing need for fishery-independent data on the state of demersal stocks, the objectives were widened to include the biology, distribution and abundance of all species that could be sampled representatively by bottom trawls. Only data collected from 1982 onwards are included here. A modified Portuguese high-headline trawl (PHHT) was chosen as the standard gear because it is relatively robust and well suited to fish the uneven and rough bottom substrata present in the area. All survey stations are fixed among years, but the number of stations visited annually varies. 


\section{Table 1. Sampling designs and gears for Celtic Sea surveys.}

Type

Institute

Vessel

Time of year

Years included

Towing speed $\left(\mathrm{km} \mathrm{h}^{-1}\right)$

Tow duration (min)

Sampling stations

Number of stations $\left(\right.$ year $\left.^{-1}\right)$

Gear

Av. swept area per tow $\left(\mathrm{km}^{2}\right)$

Horizontal trawl opening (m)

Vertical trawl opening (m)

Door type $\mathrm{m}^{2} / \mathrm{kg}$

Ground rope (m)

Head line (m)

Mesh size codend liner (mm)

Warp-length/water depth ratio

other characteristics

\author{
UK groundfish survey \\ CEFAS \\ RV "Cirolana" \\ $(72.5 \mathrm{~m}, 2 \times 820 \mathrm{~kW})$
}

s (March)
a (Nov/Dec)
s: 1982, 1984-2000
a: $1982-1988$
7.41
60
fixed
$23-50$
PHHT
0.11
14.3
4.4
$4.5 / 1440$
18.3
16
20
3.8
rubber disks
rubber bobbins
'Bunt tickler chain'

\author{
French groundfish survey \\ IFREMER \\ pre-1997: RV "Thalassa I" \\ $(66.7 \mathrm{~m}, 1323 \mathrm{~kW})$ \\ post-1997: RV "Thalassa II" \\ $(74 \mathrm{~m}, 2200 \mathrm{~kW})$ \\ a (Oct/Nov)
}

a: 1990-1991, 1997-2000

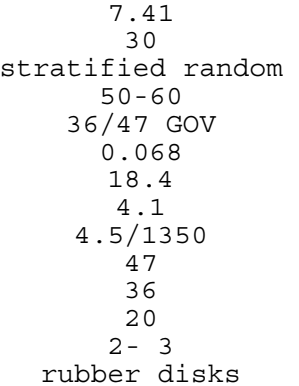

rubber disks

The French survey was initiated in 1987 to monitor changes in commercially important demersal species, in particular whiting, in the Bay of Biscay. The autumn (a) period was chosen to obtain abundance estimates of 0-group recruits. Since 1990, the survey area has been extended to include the Celtic sea and the objectives were widened to cover all fish and shellfish species. However, small benthic species are not well captured by the survey gear chosen (Chalut à Grande Overture Verticale 36/47 - GOV).

In 1990 and 1991, samples were taken on a systematic grid covering the southern and central Celtic Sea. Data for 1992-1996 were excluded because the area was not fully surveyed. In 1997, Thalassa was replaced by Thalassa II. Moreover, the survey area was extended farther north and a stratified design was implemented taking into account depth contours and geographic region, within which trawl stations were randomly selected. Analyses were restricted to the area of overlap between UK and French surveys.

The main technical differences between UK and French surveys are trawl type (PHHT vs. $36 / 47 \mathrm{GOV}$ ) and haul duration (60 vs. $30 \mathrm{~min})$, which lead to different areas swept per haul $\left(0.11 \mathrm{~km}^{2}\right.$ vs. $\left.0.068 \mathrm{~km}^{2}\right)$. In addition, the UK gear employs bobbins and a tickler chain to disturb benthic species from the bottom.

\section{- Abundance estimates}

All analyses were based on abundance and biomass estimates calculated for the whole study area. Total abundance by species was estimated according to the swept-area method, whereby mean numbers per unit area over all hauls were multiplied by the total surface area. Swept area was defined as net wingspread (horizontal opening of the net) multiplied by distance covered. For the French survey, abundance was first estimated per stratum and then summed. No correction was made for differences in catchability among species. Biomass estimates were calculated in a similar manner based on measured weight. When comparing different surveys, autumn estimates for one calendar year $(t)$ were always compared with spring estimates for the following calendar year $(t+1)$. This procedure was adopted because most species recruit to the gear during autumn and therefore, the spring and autumn surveys in the same year sample different arrays of year classes.

The differences in abundances estimates between French and English surveys and between English spring and autumn surveys were investigated on a global level (across species) and on a species level using several methods. On a global level, variance components were calculated to compare variations caused by survey period (UK spring Vs. UK autumn), sampling 
method (UK Vs. French; i.e. gear and period) and interannual variations in abundance estimates caused by sampling (inter-haul) variability. Abundance estimates were first ln-transformed to approximate normality (Trenkel and Rochet, 2003). For investigating survey-period effects, a nested model was used (including only matching years):

$$
\ln \left(\hat{N}_{i j k}\right)=\mu+\xi_{i}+\beta_{i j}+\varepsilon_{i j k},
$$

where $\hat{N}_{i j k}$ is the abundance estimate for species $i(=1, \ldots, 23)$ in survey $j$ (UK-S or UK-a) in year $k(=1984, \ldots, 1988)$. The independent random variables $\xi$ for species, $\beta$ for survey period and $\varepsilon$ for interannual variablility (residuals) have means zero and variances $\sigma_{t}^{2}, \sigma_{s}^{2}$ and $\sigma_{e}^{2}$. The corresponding sampling variance is the average of the variances of abundance estimates on the ln-scale:

$$
\sigma_{h}^{2}=\frac{1}{23 * 5 * 2} \sum_{i j k} \ln \left(\left(\hat{V}\left[\hat{N}_{i j k}\right)^{2} /\left(\hat{N}_{i j k}\right)^{2}+1\right) .\right.
$$

The model for estimating the variance component for sampling method (gear and period effect) is similar, with the random variable $\gamma$ (variance $\sigma_{m}^{2}$ ) replacing $\beta$. The relevant data series are UK-s and French-a $(\mathrm{k}=1997, \ldots, 2001)$. Only 23 species with non-zero abundance estimates for all years were included in the analysis, using a robust estimation method (minimum-norm quadratic estimator and shrinking of extreme values winsorizing); Venables and Ripley, 1994). The selected 23 species, on average, represented 98\% of assemblage abundance and 93\% of its biomass.

Principal component analysis (PCA) was used to identify the species most important for characterising the global differences in abundances estimates. Standardized abundance estimates with species as variables and annual survey estimates as individual data-points (year-survey couple) were used. All three survey series were included and again only those species present in all surveys and years.

The overall effect of survey period was tested by means of a two-way analysis of variance (ANOVA) using the UK-s and UK-a ln-transformed abundance estimates for 1982 and 1984-88 (no spring survey for 1983), with species, period and the species-period interaction as factors.

On a species level, the effect of survey period was investigated by means of a Wilcoxon paired rank test on the ln-transformed abundance estimates of the UK-S and UK-a series. The null hypothesis corresponding to no seasonal difference is that the median of the differences between autumn and subsequent spring abundance estimates (ln-transformed) is zero. Sampling method effects (owing to gear and period) were examined in the same way but using data from the UK-s survey and the French-a survey. The similarity of temporal trends for the different survey time series were investigated by examining the correlation between abundance and year using spearman's correlation coefficient $\phi$ (rank test). A comparison of test results indicated whether the two surveys suggested similar abundance trends for a particular species.

\section{- Community attributes}

The following community indicators were calculated for all three survey series: average weight of fish caught (irrespective of species), proportion of benthic species, proportion of piscivores (for classification see appendix 1), proportion of non-commercial species, species diversity, and slope and intercept of the size spectrum (Rochet and Trenkel, 2003). For species diversity, the probability that two individuals chosen at random from the community belong to different species (independent of taxonomic relatedness $\left(\Delta_{1}\right.$; range 0-1; Hurlbert, 1971) was chosen, because it is insensitive to variations in species richness caused by differences in sample size. Confidence intervals for community indicators were based on 500 parametric bootstrap samples (log-normal distributions for abundance estimates) 
Size-spectra were based on number of individuals per $5 \mathrm{~cm}$ size intervals, irrespective of species. As we are interested in the part of the spectrum that can be approximated by a linear slope, only length classes above a threshold length of $15 \mathrm{~cm}$ were included in the analysis. A linear model was fitted to ln-transformed abundances versus ln-transformed length $\left[\ln (N)=\alpha_{i}+\beta_{j}+\gamma_{j} \bullet \ln (L)\right.$, where $\alpha_{i}$ accounts for the year effect on intercepts and $\beta_{j}$ and $\gamma_{j}$ for the effects of survey type (UK-s vs. UK-a or French-a vs. UK-s) on intercepts and slopes, respectively]. The appropriate model was selected based on an analysis of deviance. All models were fitted by a Generalised Linear Model procedure with a log link and Gamma error distribution (McCullagh and Nelder, 1989). Ln(length) values were centred before analysis to avoid correlations between estimated slopes and intercepts. All statistical analyses were carried out with Splus for Unix (version 6).

\section{Results}

\section{- Global differences in abundance estimates}

The variance component for survey period $\sigma_{s}^{2}$ was less than half the size of the residual variance $\sigma_{e}^{2}$, which corresponds to the across-species interannual variance, and about the same size as the sampling variance $\sigma_{h}^{2}$ (Table 2). In contrast, in a separate analysis the sampling method variance $\sigma_{m}^{2}$ was about double the size of the interannual variance component and seven times the sampling variance. 
Table 2. Variance sampling variance.

\begin{tabular}{lccc} 
Variance component & \multicolumn{3}{c}{ Data series } \\
Species & $\sigma_{t}^{2}$ & $\begin{array}{c}\text { UK-s \& UK-a } \\
(1984-1988)\end{array}$ & $\begin{array}{c}\text { UK-s French-a } \\
(1997-2000)\end{array}$ \\
Survey period & $\sigma_{s}^{2}$ & 6.96 & 7.08 \\
Sampling method & $\sigma_{m}^{2}$ & 0.32 & 1.11 \\
Residual (Year) & $\sigma_{e}^{2}$ & & 0.56 \\
Sampling & $\sigma_{h}^{2}$ & 0.83 & 0.16
\end{tabular}

The PCA analysis showed that the species contributing most to the difference between the survey time series were T. trachurus and $S$. scombrus (positive loadings), while $H$. platessoides and $S$. caniculus contributed most with negative loadings (Table 3). E. gurnadus exhibited the least difference of all 23 species examined. When linking the data points on the first two principal component axes to the average score by survey period (spring or autumn, Figure 2 left panel) and sampling method (UK or French, Figure 2 right panel), sampling method appeared to provide more distinct groups and hence explained better the differences in abundance estimates.

Table 3. Loadings of first principal component for PCA of abundance estimates with species as variables and year-survey type couples as data points (only species present in all years and surveys are included).

$\begin{array}{lc}\text { Species } & \text { Loading } \\ \text { Hippoglossoides platessoides } & -0.83 \\ \text { Scyliorhinus canicula } & -0.79 \\ \text { Trisopterus minutus } & -0.72 \\ \text { Aspitrigla cuculus } & -0.71 \\ \text { Microchirus variegatus } & -0.71 \\ \text { Trisopterus esmarkii } & -0.67 \\ \text { Micromesistius poutassou } & -0.67 \\ \text { Argentina spp. } & -0.65 \\ \text { Microstomus kitt } & -0.58 \\ \text { Merluccius merluccius } & -0.52 \\ \text { Phycis blennoides } & -0.51 \\ \text { Gadus morhua } & -0.50 \\ \text { Glyptocephalus cynoglossus } & -0.48 \\ \text { Melanogrammus aeglefinus } & -0.43 \\ \text { Merlangius merlangus } & -0.40 \\ \text { Zeus faber } & -0.31 \\ \text { Capros aper } & -0.30 \\ \text { Limanda limanda } & -0.30 \\ \text { Eutrigla gurnadus } & 0.06 \\ \text { Helicolenus dactylopterus } & 0.08 \\ \text { Squalus acanthias } & 0.21 \\ \text { Trachurus trachurus } & 0.39 \\ \text { Scomber scombrus } & 0.40\end{array}$


A significant period effect $(F=5.08, p=0.025)$ as well as a significant species-period interaction $(F=5.15, p<0.0001)$ was detected in the ANOVA of the ln-transformed abundance estimates. The period effect was constant between years (no period-year interaction; $F=1.87, p=$ $0.10)$.

- Differences in abundance estimates by species

Overall, 98, 69 and $89 \mathrm{fish}$ species were recorded in the UK-s, UK-a, and French-a survey, respectively, but many of these were rare and appeared only intermittently in any given time-series. The ten most abundant species in terms of numbers and biomass in the French-a and UK-s series (averaged over 1997-2000; Table 4) showed a large degree of overlap, although their ranking was not the same.

Table 4. Ten most abundant species in abundance and biomass in 1997-2000 in Celtic sea as estimated from French-a and UK-s groundfish surveys (species present in all series in bold).

\begin{tabular}{lll} 
& \multicolumn{2}{c}{ Abundance } \\
Rank & French-a & UK-s \\
1 & M. poutassou & C. aper \\
2 & C. aper & T. trachurus \\
3 & T. trachurus & S. scombrus \\
4 & T. minutus & M. poutassou \\
5 & T. esmarkii & T. minutus \\
6 & Argentina spp. & S. sprattus \\
7 & S. scombrus & G. argenteus \\
8 & M. merluccius & M. merluccius \\
9 & A. cuculus & L. whiffigonis \\
10 & M. aeglefinus & Argentina spp.
\end{tabular}

\begin{tabular}{ll}
\multicolumn{2}{c}{ Biomass } \\
French-a & UK-s \\
T. trachurus & S. scombrus \\
M. poutassou & T. trachurus \\
C. aper & C. aper \\
T. minutus & M. poutassou \\
S. scombrus & M. merluccius \\
Argentina spp. & P. pollachius \\
M. aeglefinus & Argentina spp. \\
T. esmarkii & L. whiffigonis \\
M. merluccius & T. minutus \\
L. whiffigonis & Beryx spp.
\end{tabular}

Figure 2. First two components of the PCA of standardised abundance estimates using all survey data. Survey points (survey type-year couples) are linked to the barycenter for surveys carried out by France and the UK (left panel) and for those carried out in spring and autumn (right panel).

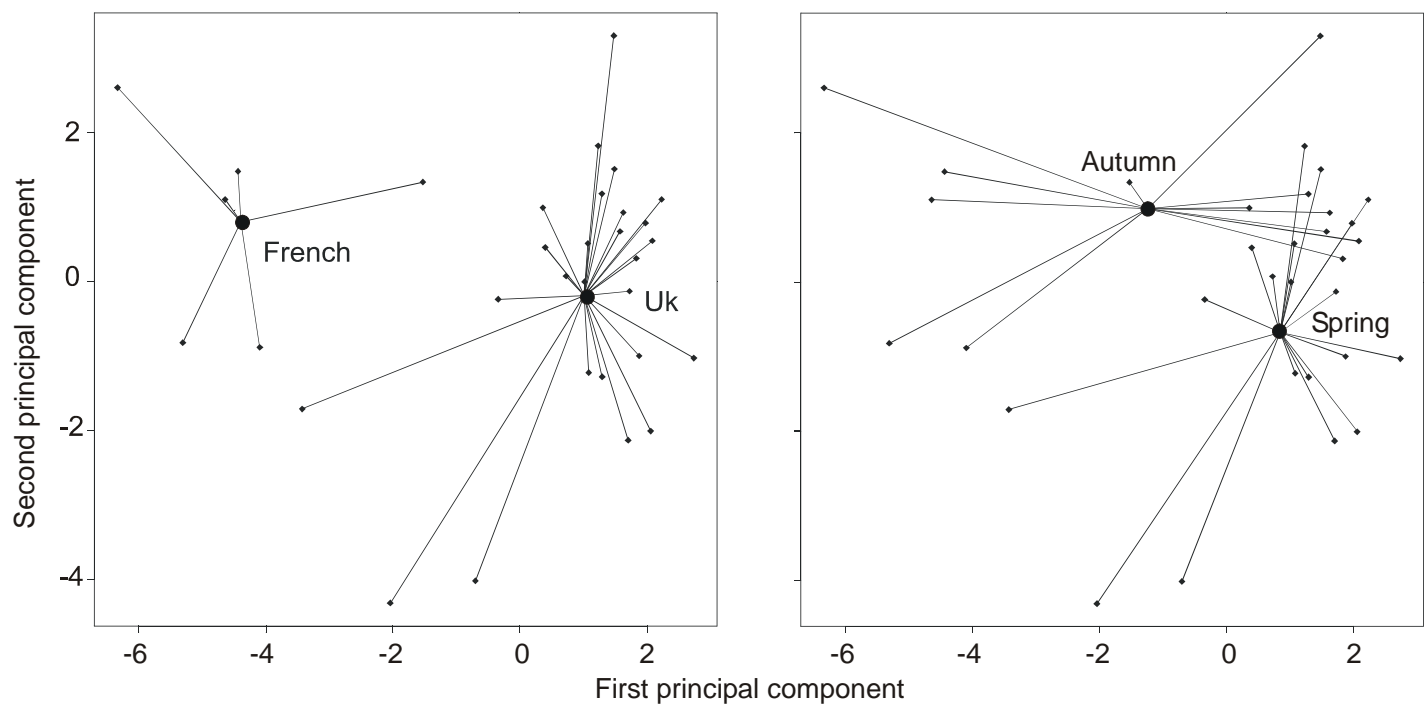

Pairwise comparisons of the UK-S and UK-a series revealed significant differences for eight out of the 24 species tested (Wilcoxon paired rank test; $\mathrm{p}<0.05)$ : M. merluccius, $M$. merlangus, $M$. kitt, $P$. virens, $S$. scombrus, T. trachurus, T. esmarkii and $Z$. faber. The relationships between the two sets of abundance estimates for the eight most abundant species are illustrated in Figure 3a. For M. merluccius, T. trachurus and S. scombrus, autumn estimates were consistently lower than spring estimates in the following calendar year. The only negative relationship between autumn and 
spring estimates was found for $T$. esmarkii. For the remaining five abundant species no consistent relationship was discernible.

When comparing French-a to UK-s series, broadly similar relationships were observed (Figure 3b). Pairwise comparisons revealed significant differences for ten out of the 40 species tested (Wilcoxon paired rank test; $\mathrm{p}<0.05)$. Among those ten, a significant season effect was found (using only UK data) for only two ( $S$. scombrus and $T$. esmarkii). Thus, for eight species the difference appears to be due to survey design rather than season.

Figure 3. Comparison of estimated annual abundances for a) UK-a (year $t$ ) and UK-s (year $t+1$ ) and b) French-a (year $t)$ and UK-s (year $t+1)$ surveys.

A
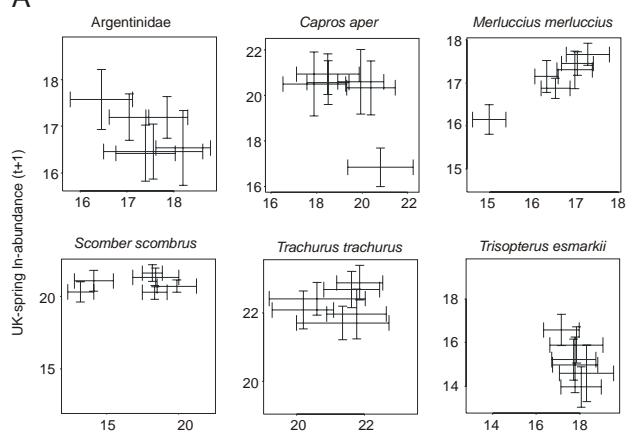

UK-autumn In-abundance (t)

B
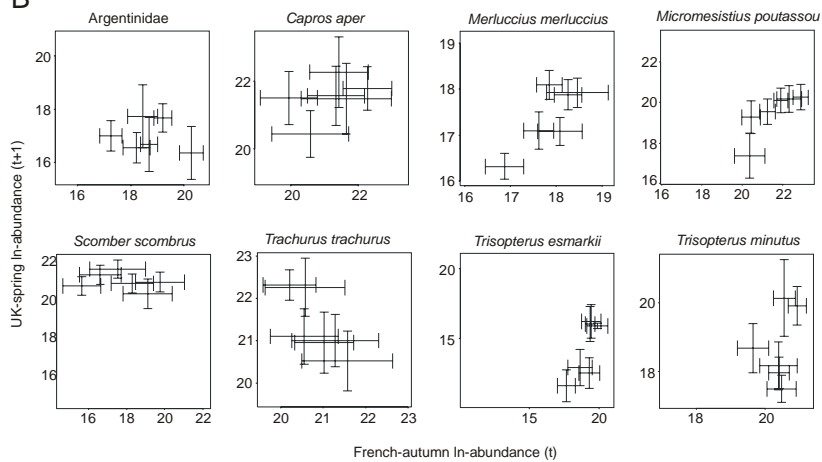

In the few cases where a significant time trend was observed, these trends differed markedly between surveys (Table 5). The abundance of $C$. aper increased significantly in the French series. An increasing trend also existed in the UK-spring series over the whole study period but not during the period of overlap with the French series (i.e. 1990-2000). T. minutus decreased significantly in French-a and UK-s surveys during the most recent years, but not over the whole 11 -year period. No significant trends in species abundance were detected for UK-s (1982-1989) and UK-a (1982-1988).

Table 5. Spearman rank correlation coefficient $(\phi)$ and $p$-values for temporal trend in abundance estimates by species.

Indicator

Argentina spp.

Capros aper

Lepidorhombus whiffigonis

\begin{tabular}{cccc} 
UK-s & \multicolumn{2}{c}{$\begin{array}{c}\text { Survey } \\
\text { French-a } \\
1991-2001\end{array}$} & \multicolumn{2}{c}{$1991-2001$} \\
$\phi$ & $p$ & $\phi$ & $p$ \\
0.15 & 0.66 & -0.37 & 0.37 \\
0.30 & 0.35 & 0.94 & 0.04 \\
-0.52 & 0.10 & 0.66 & 0.16
\end{tabular}

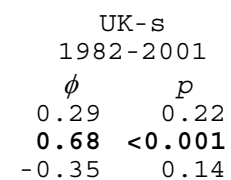


Merluccius merluccius Micromesistius poutassou scomber scombrus Trachurus trachurus Trisopterus esmarki Trisopterus minutus

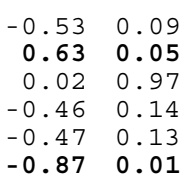

0.08

$-0.11$

0.12

$-0.68<0.001$

$-0.08 \quad 0.73$

$-0.33 \quad 0.16$

\section{- Community effects}

Figure 4 provides time series of the five community metrics derived from the three surveys. Mean weights of the fish caught were consistently smaller for both autumn data series compared to the UK-s series), but confidence limits were large and annual differences were not significant. The proportion of benthic species showed good overall agreement between surveys. A particular large value was observed for UK-s in 1995, owing to very low catches of $S$. scombrus and T. trachurus (Pinnegar et al., 2002). The proportion of benthic species increased markedly after the early 1990s, coinciding with reduced catches of horse mackerel and increased catches of $C$. aper (here considered a demersal-benthivore). The proportion represented by piscivores decreased over the whole period while the proportion of noncommercial species increased. French-a and UK-a estimates of the proportion of piscivores were generally lower than the UK-s estimates for the same years. Species diversity was broadly similar across all series but exhibited large variances.

No year effect was found for intercepts and slopes for the size spectra of all three survey series. However, the effect of season on the average slopes and intercepts was significant (1982-1989; UK-a: slope=3.07, sd=0.09; UK-s: slope=-3.55, sd=0.09), but the gear effect was much larger as the estimated slopes were far more different (1990-2000; Frencha: $\mathbf{s l o p e}=-5.27, \mathrm{sd}=0.10 ; \mathrm{UK}-\mathrm{s}$ : $\mathrm{slope}=-3.20, \mathrm{sd}=0.12 ;$ Figure 5). Very large fish $(140-200 \mathrm{~cm})$ were only caught in the French survey.

All community indices were tested for time trends (Table 6). Both the proportion of benthic species and the proportion of non-commercial species have increased significantly over the 20-year period of the UK-s survey. By contrast, the proportion of piscivores has decreased significantly. Figure 4 suggests that a marked shift in the fish community, rather than a gradual change, has occurred in the early nineties just prior to the beginning of the French time series.

Figure 4. Temporal changes in community metrics (bars: 95\% confidence intervals) for the Celtic sea groundfish assemblage sampled by UK-a (left panels), UK-s (middle panels) and French-a surveys (right panels): a) mean weight of fish in the catch; b) proportion of benthic species abundances; c) proportion of piscivore species; d) proportion of non-commercial species; and e) species diversity index $\Delta_{1}$. 

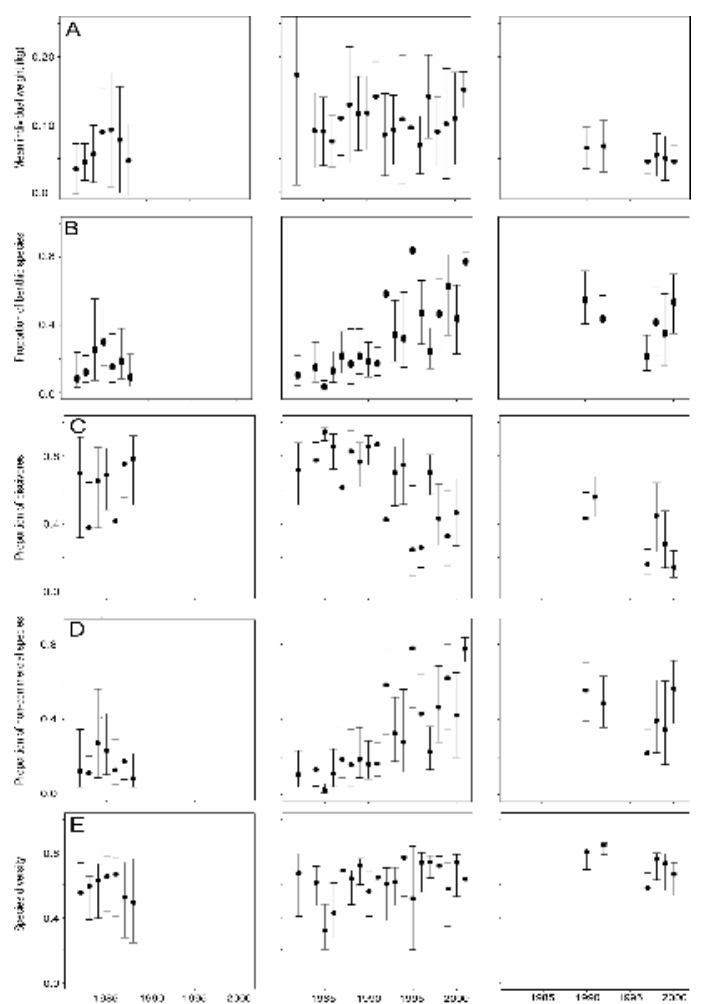

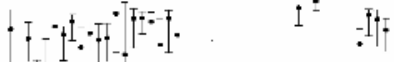

Table 6. Spearman rank correlations coefficients ( $\phi)$ and p-value for time trends of various community indicators for Celtic sea groundfish community derived from estimated abundances for UK-spring, UK-autumn and Frenchautumn surveys.

Indicator

Mean individual weight

Mean individual length

Benthic: pelagic

Proportion piscivores

Proportion non-commercial

Species diversity $\Delta_{1}$

\$: 1998-2001

*: $1997-2000$

\begin{tabular}{|c|c|c|c|c|c|c|c|c|c|}
\hline \multicolumn{2}{|c|}{$\begin{array}{r}U K-S \\
1982-89\end{array}$} & & $\begin{array}{r}\text { UK-a } \\
32-88\end{array}$ & $\begin{array}{r}\text { Sur } \\
1991\end{array}$ & $\begin{array}{l}\text { vey } \\
\text { UK-s } \\
-2001\end{array}$ & \multicolumn{2}{|c|}{ French-a } & & $\begin{array}{r}\text { UK-S } \\
32-2001\end{array}$ \\
\hline $\begin{array}{r}\phi \\
0.07\end{array}$ & 0.90 & $\begin{array}{r}\phi \\
0.54\end{array}$ & $0.2^{p}$ & $\begin{array}{r}\phi \\
0.34\end{array}$ & 0.30 & $\begin{array}{r}\phi \\
0.60\end{array}$ & $\begin{array}{r}p \\
0.16\end{array}$ & $\begin{array}{r}\phi \\
0.014\end{array}$ & 0.96 \\
\hline 0.04 & 0.97 & 0.36 & 0.41 & $0.80^{5}$ & 0.23 & $-0.80 *$ & 0.12 & -0.41 & 0.08 \\
\hline 0.79 & 0.06 & 0.18 & 0.69 & 0.41 & 0.20 & 0.26 & 0.52 & 0.86 & $<0.001$ \\
\hline 0.04 & 0.90 & 0.54 & 0.21 & 0.38 & 0.24 & 0.60 & 0.16 & -0.67 & 0.006 \\
\hline 0.79 & 0.06 & 0.11 & 0.76 & 0.43 & 0.18 & 0.03 & 1.0 & 0.86 & $<0.001$ \\
\hline 0.19 & 0.64 & 0.29 & 0.46 & 0.14 & 0.69 & 0.60 & 0.16 & 0.34 & 0.15 \\
\hline
\end{tabular}


Figure 5. Comparison of season (left panel) and gear (right panel effect on size spectra for Celtic Sea groundfish community based on UK-a/UK-s and French-a/UK-s surveys, respectively (thin: total numbers per 5-cm length class; bold: corresponding fitted linear model for sizes above $15 \mathrm{~cm}$ ).

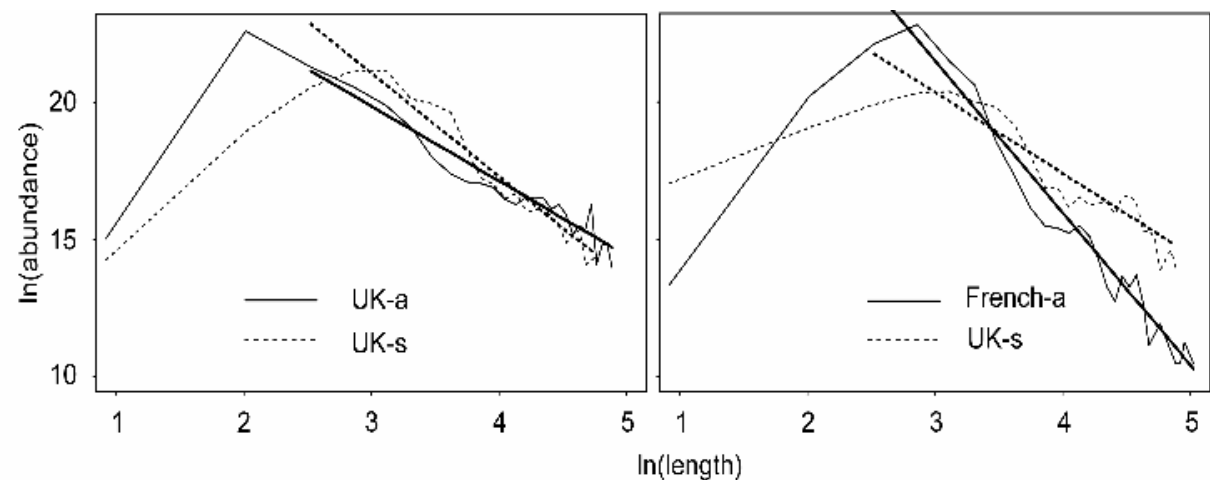

\section{Discussion}

The global analysis showed that the variance component of ln-abundance estimates for the central Celtic sea related to survey period was of similar size to the sampling variance and smaller than the interannual variability. Hence, survey period was not an important factor for the global abundance estimates from the UK surveys. In contrast, the variance component related to sampling method (gear and season) was much larger than both interannual variability and sampling variance. Taking these two results together, the global differences between UK-s and French-a surveys are more likely due to differences in survey methodology, independent of survey period. This conclusion is supported by the result that sampling method provided a better grouping of the first two principal components compared to survey period. Nevertheless, survey period was an important factor for certain species, notably hake, mackerel and horse-mackerel.

The analysis of survey differences by species showed that autumn and spring abundance estimates were sometimes negatively correlated. This might be due to the choice of the, somewhat arbitrary, study area. For certain demersal species, the area corresponds to recognized unit-stock areas used for management purposes, whereas for others it clearly did not. For instance, many pelagic species (e.g., blue-whiting, mackerel and horsemackerel) spawn in restricted areas but migrate over much larger areas of the north-east Atlantic. For many non-commercial species, no information on stock distribution and delimitation is currently available.

The French GOV trawl caught fish that were much larger than ever observed in the UK-PHHT trawl during autumn or spring surveys. Species that grow to a large size such as conger conger and squalus acanthias are commonly found in deeper waters. The difference must somehow be related to the relationship between catchability in the survey gear and fish length. The two gears appear to perform somewhat differently in deeper waters. Data for the French GOV trawl indicate that headline height decreases, and wing spread increases, with depth (Mahé, 2001). This phenomenon is known for many trawl gears (Bertrand et al., 2002), but does not seem to apply to the UK-PHHT, because no significant correlation could be demonstrated between headline height and water depth $\left(r^{2}=0.006\right)$.

There are many technical differences between the PHHT and the GOV that may result in marked differences in fish behaviour, and therefore influence catchability of particular species and/or sizes (Engås, 1994; Godø, 1994). The way in which swept area is calculated may greatly influence abundance estimates (Godø and Engås, 1989), as well as tow duration (Godø et al., 1990), time of day (Walsh, 1991) or the configuration of chains and bobbins on the groundrope (Engås and Godø, 1989). Lack of wings and a shorter head-line on the PHHT may have led to a reduced 'herding' effect. However, it is difficult to determine the importance of any particular factor without carrying out a full factorial 
trial, which is not really an option given the effort and resources this would require.

Despite differences in abundance estimates by species, time trends in community indicators were mostly absent in all time series (Table 6). Having said this, estimates of different attributes were by no means identical. Significant time trends were only detected when using the full UK-S series $(20$ years). Thus, the absence of significant trends might be due simply to the shortness of the series. Alternatively, these results might be interpreted as a lack of sensitivity of the community indicators investigated, which is supported by the large variance of their estimates, reflecting the uncertainty in the underlying abundance estimates. Nevertheless, a significant increase in recent years in the proportion of non-commercial species in the Celtic sea fish assemblage emerges in both the French and the UK-s series. This positive trend was driven by an increase in the boarfish (Capros aper), which has also been observed further south along the Galician coast (Fariña et al., 1997).

Changes in the slope and intercept of the size spectra have been suggested to follow changes in the prevailing exploitation regime (Pope et al., 1987; Murawski and Idoine, 1992; Bianchi et al., 2000). In the North Sea, steeper gradients and higher intercepts were observed in recent years and these patterns were largely attributed to the selective removal of large individuals and a possible relaxation of predation on small fish (Rice and Gislason, 1996). In the Celtic Sea, the size spectra derived from UK-S and French-a surveys differed markedly, although both were stable over the study period. The spectrum from the French survey (all years combined) had a steeper slope compared to the UK survey. Thus, the French data series might suggest a more impacted fish assemblage compared to the UK series if the absolute values of the slope were meaningful. Although the status of the Celtic sea cannot be determined on an absolute scale, the system has undergone drastic changes in recent years. For instance, total landings have increased by a factor six during the last fifty years while trophic level of landings has decreased (Pinnegar et al., 2002).

In recent years, fisheries science and management progressively have been moving away from a single-species focus towards an ecosystems approach (Anonymous, 2000; ICES, 2000). This new approach to management focuses on the development of indicators for the state and functioning of the exploited communities (Caddy and Mahon, 1995; FAO, 1999; Anonymous, 2000). Hence, the issue of indicator-based diagnostics being unbiased by sampling design has important practical implications within the context of fisheries management and natural resource management in general. Based on our results, we conclude that the use of single species abundance indices requires careful consideration of the sampling gear, season and the survey area. Because of the effect of sampling gear, we recommend that in case of changes to survey design (e.g., vessel, gear, season) data be treated as a new abundance series, or that appropriate inter-calibration studies be carried out (Pelletier, 1998).

Our results provide evidence that some community indicators are robust to sampling method. The most sensitive indicators to community changes, and incidentally the easiest to interpret, were the proportion of benthic species, the proportion of non-commercial species and the proportion of piscivores. Mean individual weight was strongly dependent on season and insensitive to apparent increases in Capros aper. By definition, the species diversity index $\Delta_{1}$ cannot reveal replacement effects and hence seems not well suited for general use in a management context. Similarly, owing to the effect of sampling method on size spectra, only consistent time series can be interpreted.

\section{Acknowledgements}

We thank all people involved in the data collection, in particular J.-C. Mahé, J.-C. Poulard and S. Warnes. The study was funded by the European Community under Framework V, project QLRT-1999-01609 (Development of structurally detailed statistically testable models of marine populations, $d s t^{2}$ ) and the UK Department for Environment, Food and Rural Affairs contract MF0316. We also thank C. O'Brien, B. Mesnil and two referees for providing comments on the manuscript. 


\section{References}

Anonymous 2000. Special Issue: Sustainability indicators in marine capture fisheries. Marine and Freshwater Research, 51: 381-541.

Bertrand, J., Leonori, I., Dremière, P., and Cosimi, G. 2002. Depth trajectory and performance of a trawl used for an international bottom trawl survey in the Mediterranean. Scientia Marina, 66 (Supplement 2): 169182 .

Bianchi, G., Gislason, H., Graham, K., Hill, L., Jin, X., Goranteng, K., Manickchand-Heileman, S., Payá, L., Sainsbury, K., Sanchez, F., and Zwanenburg, K. 2000. Impact of fishing of size composition and diversity of demersal fish communities. ICES Journal of Marine Science, 57: 558-571.

Caddy, J.F., and Mahon, R. 1995. Reference points for fisheries management. FAO Fisheries Technical Paper, $\mathrm{N}^{\circ} 347, \mathrm{FAO}$, Rome. 83pp.

Cao, Y., Williams, D.D., and Larsen, D.P. 2002. Comparison of ecological communities: the problem of sample representativeness. Ecological Monographs, $72: 41-56$.

Engås, A. 1994. The effects of trawl performance and fish behaviour on the catching efficiency of demersal sampling trawls. In Marine fish behaviour in capture and abundance estimation, pp 45-68. Ed. by A. Fernö and S. Olsen S. Fishing News Books, Oxford. 221pp.

Engås, A., and Godø, O.R. 1989. Escape of fish under the fishing line of a Norwegian sampling trawl and its influence on survey results. Journal du Conseil International pour l'Exploration de la Mer, 45: 269-276.

FAO 1999. Indicators for sustainable development of marine capture fisheries. FAO Technical Guidelines for Responsible Fisheries, $N^{\circ} 8$, FAO, $^{\circ}$ Rome. $68 \mathrm{pp}$.

Fariña, A., Freire, J., and González-Gurriarán, E. 1997. Demersal fish assemblages in the Galician continental shelf and upper slope (NW Spain): Spatial structure and long-term changes. Estuarine, Coastal and shelf Science, 44: 436-454.

Godø, O., and Engås, A. 1989. Swept area variation with depth and its influence on abundance indices of groundish from trawl surveys. Journal of Northwest Atlantic Fisheries Sciences, 3: 133-139.

Godø, O., Pennington, M., and Vølstad, J. 1990. Effect of tow duration on length composition of trawl catches. Fisheries Research, 9: 165-179.

Godø, O.R. 1994. Natural fish behaviour and catchability of groundfish. ICES Annual Science Conference, ICES CM 1994/B:14. 11pp.

Goldwasser, L., and Roughgarden, J. 1997. Sampling effects and the estimation of food-web properties. Ecology, 78: 41-54.

Greenstreet, S.P.R. 1996. Estimation of the daily consumption of food by fish in the North sea in each quarter of the year. Scottish Fisheries Report $\mathrm{N}^{\circ}$ 55, Fisheries Research Services, Aberdeen. 16pp.

Greenstreet, S.P.R., Spence, F.E., and McMillan, J.A. 1999. Fishing effects in northeast Atlantic shelf seas: patterns in fishing effort, diversity and community structure. $V$ Changes in structure of the North Sea groundfish species assemblage between 1925 and 1996. Fisheries Research, 40: 153-183.

Hövemeyer, K., and Stippich, G. 2000. Assessing spider community structure in a beech forest: Effects of sampling method. European Journal of Entomology, 97: 369-375. 
Hurlbert, S.H. 1971. The nonconcept of species diversity : a critique and alternative parameters. Ecology, 52: 577-586.

Hollingworth, C.E. (Ed.), 2000. Ecosystem effect of fishing. Proceedings of an ICES/SCOR Symposium held in Montpellier, France, 16-19 March 1999. ICES Journal of Marine Science, 57: 465-792.

Kulbicki, M., and Wantiez, L. 1990. Comparison between fish bycatch from shrimp trawlnet and visual census in St. Vincent Bay, New Caledonia. Fishery Bulletin, 88: 667-675.

Lockwood, S.J., and Shepherd, J.G. 1984. An assessment of the Western mackerel stock. Journal du Conseil International pour l'Exploration de la Mer, 41: 167-180.

Mahé, J.-C. 2001. International program of standardised trawl surveys. Report No. Contract 98-057, Ifremer, Lorient

McCullagh, P., and Nelder, J.A. 1989. Generalized linear models, 2nd Edition, London, Chapman and Hall, 511pp

Merrett, N.R., Gordon, J.D.M., Stehmann, M., and Haedrich, R.L. 1991. Deep demersal fish assemblage structure in the Porcupine seabight (Eastern North Atlantic): Slope sampling by three different trawls compared. Journal of the Marine Biological Association U.K., 71: 329-358.

Murawski, S.A., and Idoine, J.S. 1992. Multispecies size composition: A conservative property of exploited fishery systems? Journal of Northwest Atlantic Fishery Science, 14: 79-85.

O'Neill, R.V. 2001. Is it time to bury the ecosystem concept? (with full military honors, of course!). Ecology, 81: 3275-3284.

Pelletier, D. 1998. Intercalibration of research survey vessels in fisheries: a review and an application. Canadian Journal of Fisheries and Aquatic Sciences, 55: 2672-2690.

Pinnegar, J.K., Jennings, S., O'Brien, C.M., and Polunin, N.V.C. 2002. Long-term changes in the trophic level of the Celtic sea fish community and fish market price distribution. Journal of Applied Ecology, 39: 377-390.

Polovino, H.N., Farrell, M.P., and Pennington, C.H. 1982. An evaluation of community information indices for Mississipi River fisheries. Oak Ridge National Laboratory, Report $\mathrm{N}^{\circ}$ ORNL/TM-8272. 72pp.

Pope, J., Stokes, T., Murawski, S.A., and Idoine, J.S. 1987. A comparison of fish size composition in the North sea and on Georges Bank. In Ecodynamics, contributions to theoretical ecology, pp 146-152. Eds. W. Wolff, C.-J. Soeder and F.R. Drepper. Springer Verlag, Berlin, $349 \mathrm{pp}$.

Rice, J., and Gislason, H. 1996. Patterns of change in the size spectra of numbers and diversity of the North sea fish assemblage, as reflected in surveys and models. ICES Journal of Marine Science, 53: 1214-1225

Rochet, M.J., and Trenkel, V.M. 2003. Which community indicators can measure the impact of fishing ? A review and proposals. Canadian Journal of Fisheries and Aquatic Sciences, 60: 86-99.

Soetaert, K., and Heip, C. 1990. Sample-size dependence of diversity indices and the determination of sufficient sample size in a high-diversity deep-sea environment. Marine Ecology Progress Series, 59: 305-307.

Trenkel, V.M., and Rochet, M.-J. 2003. Performance of indicators derived from abundance estimates for detecting the impact of fishing on a fish community. Canadian Journal of Fisheries and Aquatic Sciences, 60: 67-85.

Venables, W.N., and Ripley, B.D. 1994. Modern applied statistics with SPlus. Springer Verlag, Berlin, $462 \mathrm{pp}$. 
Walsh, S.J. 1991. Diel variation in availability and vulnerability of fish to a survey trawl. Journal of Applied Ichthyology, 7: 147-159.

Wantiez, L. 1996. Comparison of fish assemblages sampled by a shrimp trawl and a fish trawl in St Vincent Bay, New Caledonia. Journal of the Marine Biological Association, U.K., 76: 759-775.

Warwick, R.M., and Clarke, K.R. 1996. Relationships between body-size, species abundance and diversity in marine benthic assemblages: facts or artefacts? Journal of Experimental Marine Biology and Ecology, 202: 63-71.

Whitehead, P.J.P., Bauchot, M.-L., Hureau, J.-C., Nielsen, J., and Tortonese, E. (eds) 1986. Fishes of the North-eastern Atlantic and the Mediterranean, 3 Volumes. UNESCO, $1473 \mathrm{pp}$.

Yodzis, P., and Winnemiller, K.O. 1999. In search of operational trophospecies in a tropical aquatic food web. Oikos, 87: 327-334. 


\section{Appendix 1}

Classification of fish species into trophic guilds (PEPA = pelagic planktivore; $\mathrm{PEPI}=$ pelagic piscivore; $\mathrm{DEBE}=$ demersal benthivore; $\mathrm{DEPI}=$ demersal piscivore; source: Whitehead et al., 1986; Greenstreet, 1996; na = not available) and identification of commercial species ( $\mathrm{Y} / \mathrm{N})$.

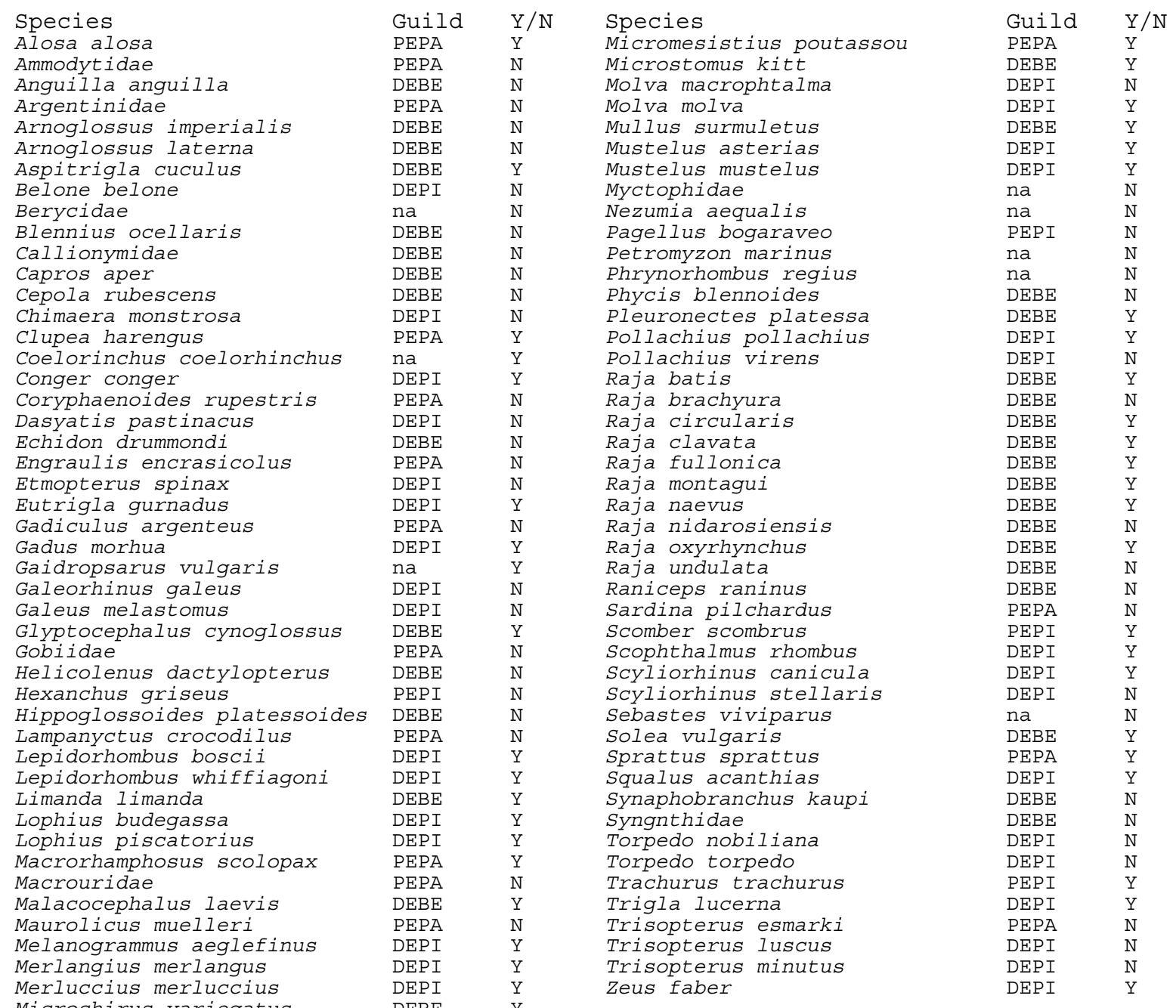

